\title{
The photosynthesis of individual algal cells during the cell cycle of Scenedesmus quadricauda studied by chlorophyll fluorescence kinetic microscopy
}

\author{
E. Šetlíková ${ }^{1,2}$, I. Š Setlík $^{1,2, *}$, H. Küpper ${ }^{2,3}$, V. Kasalický1 ${ }^{1,2}$ \& O. Prášil ${ }^{1,2}$ \\ ${ }^{1}$ Institute of Microbiology, Academy of Sciences of the Czech Republic, 37981, Třeboň, Czech Republic; \\ ${ }^{2}$ Faculty of Biological Sciences and Institute of Physical Biology, University of South Bohemia, Branišovská \\ 31, 37005 České Budejovice, Czech Republic; ${ }^{3}$ Mathematisch-Naturwissenschaftliche Sektion, Fachbereich \\ Biologie, Universität Konstanz, 78457 Konstanz, Germany; *Author for correspondence (e-mail: setlik@) \\ alga.cz; fax: + 420-384-721246)
}

Key words: cell cycle, chlorophyll fluorescence kinetics, fluorescence microscopy, regulation of photosynthesis, Scenedesmus, single cells, variable chlorophyll fluorescence

\begin{abstract}
A microscope for imaging of chlorophyll fluorescence kinetics was equipped with a chamber that allows the growth of an immobilised population of algae and their study under well-defined conditions. Single cells of the chlorococcal alga Scenedesmus quadricauda were grown and recorded for periods of whole cell cycles (up to $48 \mathrm{~h}$ ) displaying a normal course of cell development. Heterogeneity in fluorescence yield among individual coenobia in the population and among different cells in one coenobium were analysed. Differences were observed both in the shape of Kautsky transients and in the modulation of fluorescence parameter values during the progress of the cell cycle. The extent of heterogeneity in fluorescence parameters was cell cycle dependent - in some phases of the cycle, the population was almost homogeneous, while distinct heterogeneity was observed, in particular between the protoplast division and the release of the daughter coenobia. The heterogeneity was not random but reflected developmental processes.

Abbreviations: AI - actinic irradiance; $\mathrm{CC}$ - cell cycle; $F_{\mathrm{m}}$ and $F_{\mathrm{m}}^{\prime}$ - maximum fluorescence yield in the dark adapted state and in the light adapted state, respectively; $F_{0}$ and $F_{0}^{\prime}$ - minimum fluorescence yield in the dark adapted and the light adapted state, respectively; $\Phi_{\mathrm{P}}-$ effective quantum yield of PS II photochemistry in the light adapted state; $\Phi_{\mathrm{PS} \text { II }}$ - effective quantum yield of photochemical energy conversion in Photosystem II; $F q$ - difference between the maximal and actual fluorescence in the light adapted state, often labelled $\Delta F ; F_{\mathrm{t}}$ - actual fluorescence at time $t ; F_{\mathrm{v}}$ and $F_{\mathrm{v}}^{\prime}$ - the yield of variable fluorescence in the dark adapted and the light adapted state, respectively; FY - fluorescence yield; MGC - measuring growth chamber; NPQ - non- photochemical quenching, used in the text as a non-specific name of the phenomenon; PS I - Photosystem I; PS II - Photosystem II; $q_{\mathrm{NP}}$ - non-photochemical quenching, calculated quantity, normalised to $F_{\mathrm{m}} ; q_{\mathrm{P}}-$ fraction of the PS II RCs actually open in the light adapted state
\end{abstract}

\section{Introduction}

Synchronously growing populations of unicellular algae are excellent tools for investigations of structural and functional changes of the photosynthetic apparatus in the course of the cell cycle (Berková et al. 1972; Šetlík et al. 1981; Kaftan et al. 1999; Strasser et al. 1999 ). However, even the 
best-synchronised population, maintains a certain statistical distribution of cell-specific parameters. We have recently developed a method for recording two-dimensional (imaging) chlorophyll fluorescence kinetics in single cells (Küpper et al. 2000) that challenged us to make an attempt to assess the width of this distribution.

The cell cycles of several algal taxa are characterised by multiple fissions (Šetlík and Zachleder 1984) where several replications of DNA and several nuclear divisions are followed by the corresponding number of cellular divisions. Scenedesmus quadricauda is a classical example of this type of cell cycle and serves as a model organism for its analysis (Zachleder et al. 2002). In Scenedesmus, the daughter cells resulting from the multiple fission remain joined to the so-called coenobium. For example, the eightcell coenobia result from a multiple fission following three nuclear divisions. Pronounced changes in photosynthetic activity of Scenedesmus quadricauda in the course of the cell cycle can be correlated with distinct developmental stages that have been defined mainly by the consecutive commitments to DNA replications and nuclear divisions (Berková et al. 1971, Śetlík et al. 1972).

Fluorescence kinetics imaging is an important tool for determination of heterogeneity of photosynthetic processes at levels ranging from whole canopies to single cells. So far, only one report dealt with photosynthetic microorganisms (Oxborough et al. 2000), but it was focused solely on differences between species and not on modulation of photosynthesis during the development of their photosynthetic apparatus.

To our knowledge, we present here the first results of an observation in which the photosynthetic behaviour of selected individuals in a population of algal cells has been followed in the course of the whole cell cycle. We have used fluorescence transients to calculate several photosynthetic parameters. We estimated changes in these parameters during development of individual cells and extent of their heterogeneity in the population. In addition, we present the first systematic study of fluorescence transients in an algal cell cycle.

\section{Materials and methods}

The chlorococcal alga Scenedesmus quadricauda (Turp.) BrÉB (strain Greifswald 15, CCALA \#463) was obtained from the CCALA algal collection maintained in Třeboň, Czech Republic (http:// www.butbn.cas.cz/ccala/ccala.htm). The cells were pre-grown at $28{ }^{\circ} \mathrm{C}$ in suspension cultures synchronised by irradiance cycles of $14 \mathrm{~h}$ light, $10 \mathrm{~h}$ darkness in the mineral medium (detailed composition in Šetlík et al. 1981). The irradiance regime was computer-controlled and simulated the daily course of solar radiation with maximum irradiance at noon $1000 \mu \mathrm{mol} \mathrm{m} \mathrm{m}^{-2} \mathrm{~s}^{-1}$ supplied by Osram (Munich, Germany) Dulux EL fluorescent tubes (Havelková-Doušová et al. 2004). For the microscopic recordings shown in this paper, several daughter coenobia were taken from such synchronous populations. A drop of concentrated cell suspension was placed on the inner surface of the microscope growth chamber (described in Küpper et al. 2000), that allows to grow, for periods of days, a monocellular layer of microscopic algae under controlled conditions. The light for growth of algae in the microscope growth chamber was provided by a custom-designed white LED irradiation source. For the current experiments, the microscope growth chamber has been modified by a new temperature stabilisation. A thermoelectric couple was connected to the Teflon-covered metal body of the growth chamber to equilibrate the temperature of the incoming medium that flushes the membrane protecting the layer of algae. Cells in the growth chamber were fixed by a stretched cellophane foil that allowed exchange of ions and gases with the medium flowing through the chamber.

The fluorescence kinetic microscope (FKM) has been constructed in collaboration with the company Photon Systems Instruments (Brno, Czech Republic, www.psi.cz), on the basis of a Fluoval microscope (Carl Zeiss, Jena, Germany) as described by Küpper et al. (2000) and Ferimazova et al. (2002). Fluorescence yield (FY) was recorded by a PC computer using the software FluorCam (Photon Systems Instruments) and user-defined protocols. For all measurements reported here, we designed a protocol that reveals the main dark-light transients in the initial phase of relaxation of non-photochemical quenching (NPQ) in the dark. The FY transients obtained with this protocol are illustrated in Figure 1. The measurement started with one multiple-turnover saturating irradiation pulse that excited maximal FY of the dark-adapted state $\left(F_{\mathrm{m}}\right)$. After $90 \mathrm{~s}$ of 

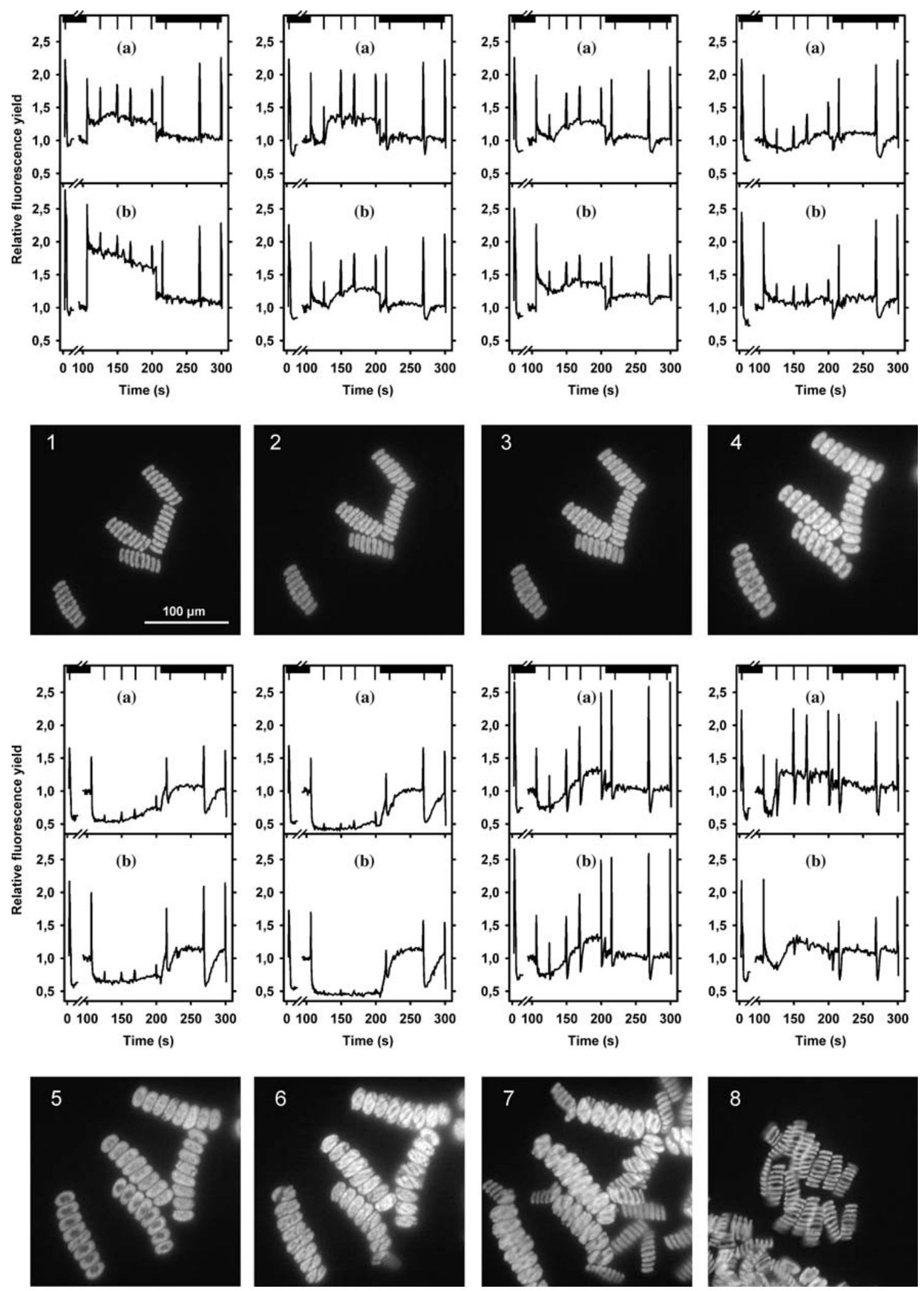
Figure 1. Records of fluorescence yield in eight cell cycle stages of Scenedesmus quadricauda grown in the MGC under irradiance of $250 \mu \mathrm{mol} \mathrm{m} \mathrm{m}^{-2} \mathrm{~s}^{-1}$. The medium flushing the chamber was kept at $28{ }^{\circ} \mathrm{C}$ in equilibrium with air containing $0.5 \mathrm{kPa} \mathrm{CO}_{2}$. The images of fluorescence were recorded by a b/w camera. The records labelled 'a' were measured with AI of $40 \mu \mathrm{mol}^{\mathrm{photons}} \mathrm{m}^{-2} \mathrm{~s}^{-1}$ and those labelled 'b' with $120 \mu \mathrm{mol}$ photons $\mathrm{m}^{-2} \mathrm{~s}^{-1}$. FY values are normalised to $F_{0}$. The black rectangles at the top of each panel indicate the periods of darkness and the downward ticks position of saturating irradiation pulses applied during actinic irradiation and subsequent darkness. The first $6 \mathrm{~s}$ of the record are shown on an extended time scale.

darkness, the minimum FY $\left(F_{0}\right)$ was recorded for $10 \mathrm{~s}$ and the actinic irradiation started at $106 \mathrm{~s}$ of the record. Four saturating irradiation pulses were then applied during actinic irradiation at 125, 150, 170 and $199 \mathrm{~s}$ (in the text referred as the first, second, etc. pulse) to measure the maximal FYs in the light adapted state $\left(F_{\mathrm{m}}^{\prime}\right)$. AI was switched-off at $205 \mathrm{~s}$ and three saturating irradiation pulses were then applied in the dark at 220, 270 and 295 s. The duration of the record was limited mainly by two factors: the size of the primary data file and the time required for the measurement. Since during all phases of measurements the growth irradiance was switched-off, we tried to minimise the disturbance of the progress in the cell cycle by intermissions caused by measurements. Fluorescence parameters were calculated from measured values as in Oxborough and Baker (1997) including their formula for calculation of $F_{0}^{\prime}$. Non-photochemical quenching is given as a value normalised to $F_{\mathrm{m}}$, i.e., $q_{\mathrm{NP}}=\left(F_{\mathrm{m}}-F_{\mathrm{m}}^{\prime}\right) / F_{\mathrm{m}}$. During this study we have recorded data from 38 cell cycles. The results shown here are representative of these and show all typical features of the observed phenomena.

\section{Results and discussion}

Figure 1 shows records of Kautsky fluorescence transients throughout one cell cycle (CC). They show the variation in averaged FY of two Scenedesmus coenobia. The displayed records were taken at an actinic irradiance of $40 \mu \mathrm{mol}$ photons $\mathrm{m}^{-2} \mathrm{~s}^{-1}$ (graphs labelled a) and $120 \mu \mathrm{mol}$ photons $\mathrm{m}^{-2} \mathrm{~s}^{-1}$ (graphs labelled $\mathrm{b}$ ). These actinic irradiances are approximately $1 / 3$ and $2 / 3$ of the irradiance saturating the overall photosynthesis, respectively. The timing of the representative cell cycle stages 1-8 was selected so as to represent distinct phases in coupling of photosynthetic processes with developmental and reproductive events of Scenedesmus cells (Berková et al. 1972). In this paper they are defined as follows: (1) daughter coenobia just after division of the mother cells; (2) cells at the maximum rate of development of the photosynthetic apparatus; (3) cells after passing the first commitment point and displaying the maximum activity of photosynthesis; (4) start of the decline of Photosystem II activity and preparation for the second commitment; (5) cells after passing second commitment point, strong decline of photosynthetic activity; (6) start of protoplast division, minimum of photosynthetic activity; (7) protoplast division nearly completed, starting recovery of photosynthetic activity; (8) liberation of daughter coenobia from mother cells, photosynthetic activity returning to stage 1 . The growth irradiance was switched-off between the CC stages 5 and 6 , i.e., in about $3 / 5$ of the total duration of CC. The image No. 6 of Figure 1 shows that cells have already divided their protoplasts and that the daughter coenobia need only to terminate their formation and to be released from the cell wall of the mother cell.

The shapes of Kautsky fluorescence transients vary considerably at various $\mathrm{CC}$ stages and at different levels of actinic irradiance. Figure 1 illustrates several features. The initial rise of FY upon the onset of actinic irradiation forms, even at low irradiance, a sharp peak from which FY abruptly drops to $F_{\mathrm{t}}$. $F_{\mathrm{t}}$ then often falls below the $F_{0}$ level (Figure 1, panels $1-5 \mathrm{a}, \mathrm{b}$ to $8 \mathrm{a}, \mathrm{b}$ ). Even at low actinic irradiance, this state has a character of strong non-photochemical quenching with no response to saturating irradiation pulses. Cells in this state display also other characteristic features: (1) The FY immediately after the first saturating irradiation pulse in the record (1-6 s) is well below $F_{0}$. (2) When the actinic irradiation is switched-off, $F_{\mathrm{t}}$ rises back to $F_{0}$ usually quite rapidly (in about $30 \mathrm{~s}$ ), often with a temporary overshoot to higher values (cf. Figure 1, panel 6b).

If present, the just described shape of Kautsky fluorescence transients can be observed through several CC stages and becomes most conspicuous in the period of protoplast division and daughter cell formation (CC stages no. 5 and 6 in Figure 1). In $\mathrm{CC}$ stages between protoplast division and the 
liberation of autospores (stages no. 7 and 8) the drop of $F_{\mathrm{t}}$ below $F_{0}$ is transient and, following an interval of variable duration, it rises above the $F_{0}$ level still during actinic irradiation. In the same period of the CC, the saturating irradiation pulses are followed by dramatic transient drops of FY below $F_{\mathrm{t}}$, both in actinic irradiation period and in subsequent darkness. In fact, less pronounced negative overshoots of fluorescence signal following saturating irradiation pulses are a common feature of the Scenedesmus fluorescence transients under low actinic irradiance. They are particularly distinct in the final CC stages and sometimes the downward overshoot is followed by another upward peak or even a strongly damped oscillation.

The decrease of $F_{\mathrm{t}}$ below $F_{0}$ during actinic irradiation can reflect presence of very strong NPQ that reduces $F_{0}$ sometimes as much as to half of its non-quenched value and may totally suppress the response to saturating irradiation pulses (Figure 1, panels $6 \mathrm{a}, \mathrm{b}$ ). This explanation is, however, at variance with the fast rise of $F_{\mathrm{t}}$ and an early recovery of $F_{\mathrm{m}}$ upon darkening, and it can hardly explain the repeatedly occurring overshoots of $F_{\mathrm{t}}$. A more likely explanation involves interactions of the photosynthetic electron transport with different respiratory processes (chlororespiration or mitorespiration). The latter, as well as the cyclic electron flow around PS I, are known to energise the thylakoid membrane and to reduce the plastoquinone pool (Cournac et al. 2002; Peltier and Cournac 2002). The overshoots of FY to levels below $F_{0}$, followed sometimes by rudiments of oscillations in FY, remind the interference of light pulses with respiration (cf. also Ried et al. 1973). Finally, thylakoid energisation might also result from the Mehler reaction that operates to provide enough ATP for $\mathrm{HCO}_{3}^{-}$accumulation in the cells. Taking all this into account, we may speculate that the FY value attained after $90 \mathrm{~s}$ of dark adaptation is not the true $F_{0}$ value, but reflects instead an increased FY resulting from a partial backreduction of $\mathrm{Q}_{\mathrm{A}}$ by the $\mathrm{PQ}$ pool that is reduced in the dark by respiratory processes. The low $F_{\mathrm{t}}$ then would not reflect the non-photochemical quenching, but the reoxidation of reduced $\mathrm{Q}_{\mathrm{A}}$ by linear electron flow.

In Figure 2 we present the cell cycle-dependent changes of several fluorescence parameters that were calculated either from the fluorescence kinetic records illustrated in Figure 1 (cell cycle B, Figure 2, panels e-h) or from another cycle (cell cycle A, Figure 2, panels a-d). The two cycles differed in their growth conditions (as specified in the legend to Figure 2) and consequently also in the rates of growth and development of the cells. As a consequence, pronounced differences exist between the two CCs, both in the time-course of variations in fluorescence parameters and in the extent of heterogeneity between individual coenobia. The averaged course of the fluorescence parameter values is, however, in general agreement with previous reports about changes of photosynthetic activity in synchronous $S$. quadricauda populations (cf. e.g., Berková et al. 1972; Šetlík et al. 1981). The values of $\Phi_{\mathrm{PS} \text { II }}$ are maximal in the first hours of the light period (CC stages 2 and 3 ) after which they decline to reach a minimum during protoplast division (CC stages 6 and 7). Thereafter, the activity of the photosynthetic apparatus again rises in parallel with the formation of daughter coenobia. The course of various fluorescence parameters documents the homeostasis of photosynthesis during the $\mathrm{CC}$ : changes in $q_{\mathrm{P}}$ run approximately antiparallel to changes in $\Phi_{\mathrm{p}}$ so that the relative variation of $\Phi_{\mathrm{PS}}$ II during the course of $\mathrm{CC}$ is small.

The degree of heterogeneity in FY among individual coenobia depends on the previous history of the algal population and on growth conditions during the experiment. It is much more pronounced in the cell cycle B than in cell cycle A of Figure 2. For cell cycle A, changes in fluorescence parameters are shown for the group of coenobia in the whole field of view or for four selected coenobia (coenobium 1 to 4 ) that have been analysed individually. In cell cycle B, only three individually analysed cells from one field of view are documented. Results from both cycles show that the degree of divergence in the values of the parameters is cell cycle-dependent. It is low in some CC stages but increases in others. It is particularly high towards the end of cell cycle. Not only the divergence of values in fluorescence parameters among individual coenobia, but also their rank change during the cell cycle.

The time course of fluorescence parameters of individual cells in one coenobium (Figure $3 \mathrm{e}-\mathrm{h}$ ) shows the same principal features like whole coenobia. The most pronounced heterogeneity is observed during stages of protoplast and cell 

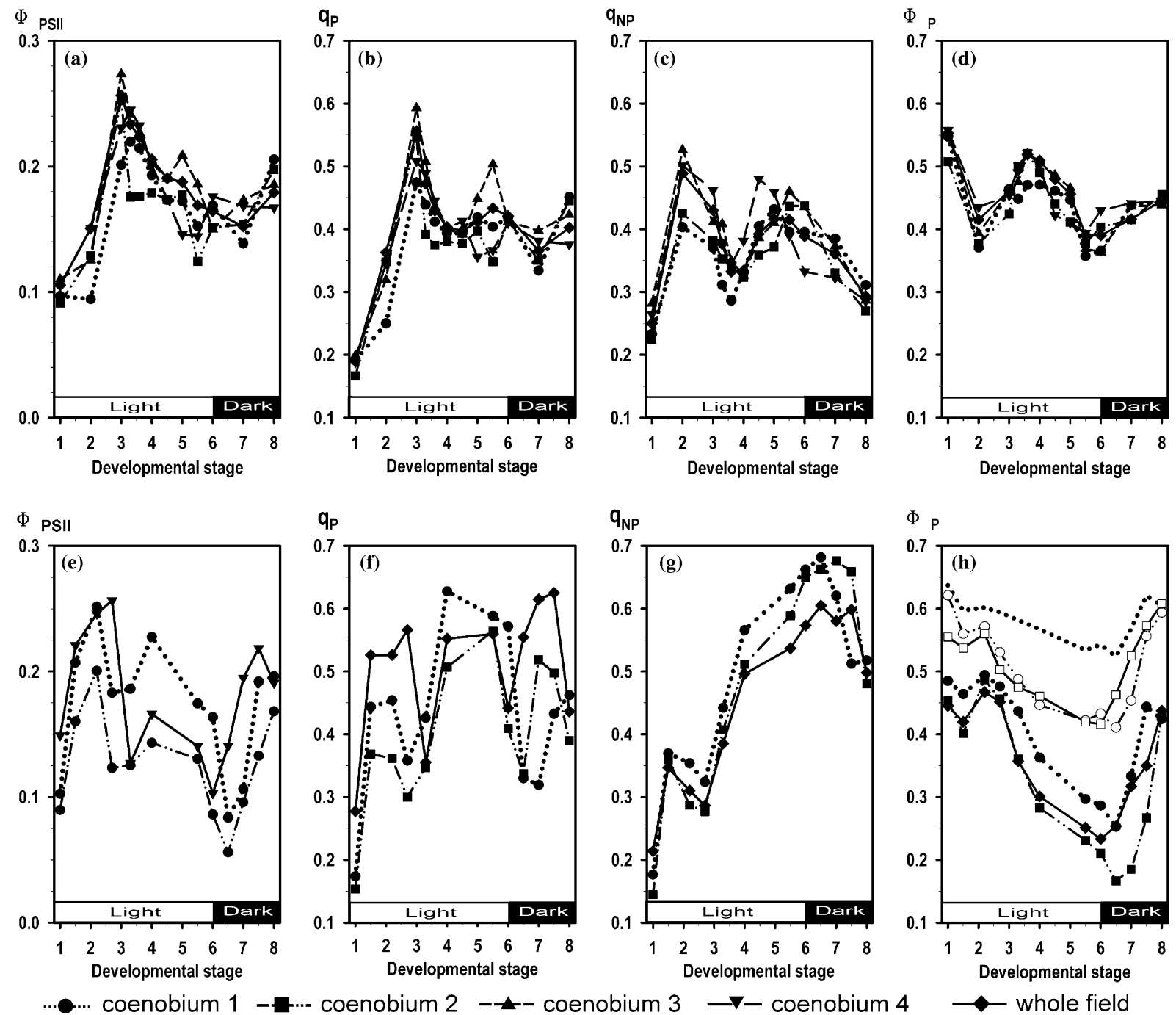

Figure 2. Differences among individual coenobia in the variation of fluorescence parameters in the course of two cell cycles. The cells that yielded curves in (a-d) (cell cycle A) were grown in the MGC at an irradiance of $120 \mu \mathrm{mol}$ photons $\mathrm{m}^{-2} \mathrm{~s}^{-1}$ and with $1 \mathrm{mmol} \mathrm{CO}$ $\mathrm{I}^{-1}$ of nutrient solution. Curves illustrated in (e-h) (cell cycle B) characterise cells grown at $250 \mu \mathrm{mol}$ photons $\mathrm{m}^{-2} \mathrm{~s}^{-1}$, and with $0.25 \mathrm{mmol} \mathrm{CO}_{2} \mathrm{l}^{-1}$. The fluorescence parameters were calculated from records of FY taken at an actinic irradiance of $120 \mu \mathrm{mol}$ photons $\mathrm{m}^{-2} \mathrm{~s}^{-1}$ and the quantities measured during actinic irradiance refer to the third saturating irradiation pulse. The fluorescence parameters plotted in individual panels are indicated on the respective $y$-axis. The $x$-axis indicates progress of cell cycle time by the numbers of the characteristic cell cycle stages. The labelling of the curves is shown at the bottom of the figure. For cell cycle A the courses of the fluorescence parameters are shown for four coenobia selected in one field of view and for the integral signal from all coenobia in the field (whole field). For cell cycle B only fluorescence parameters for three separately analysed coenobia are shown.

division and when liberation of daughter cells occurs. Figures $3 \mathrm{a}-\mathrm{c}$ show examples of how differences in the shape of Kautsky fluorescence transient for four cells in the coenobium (Figure 3d) gradually develop in the later stages of the cell cycle. These differences in kinetics are then reflected in differences in fluorescence parameter values. Figure 3 also shows that changes in fluorescence parameters are mostly similar for the outer cells in a coenobium (cells 1 and 8) on one hand and for the inner cells (4 and 6) on the other, while distinct differences can be seen between the two groups of cells. This heterogeneity is in line with the known fact that in the coenobium the outer cells develop at a noticeably different rate than the inner ones. 

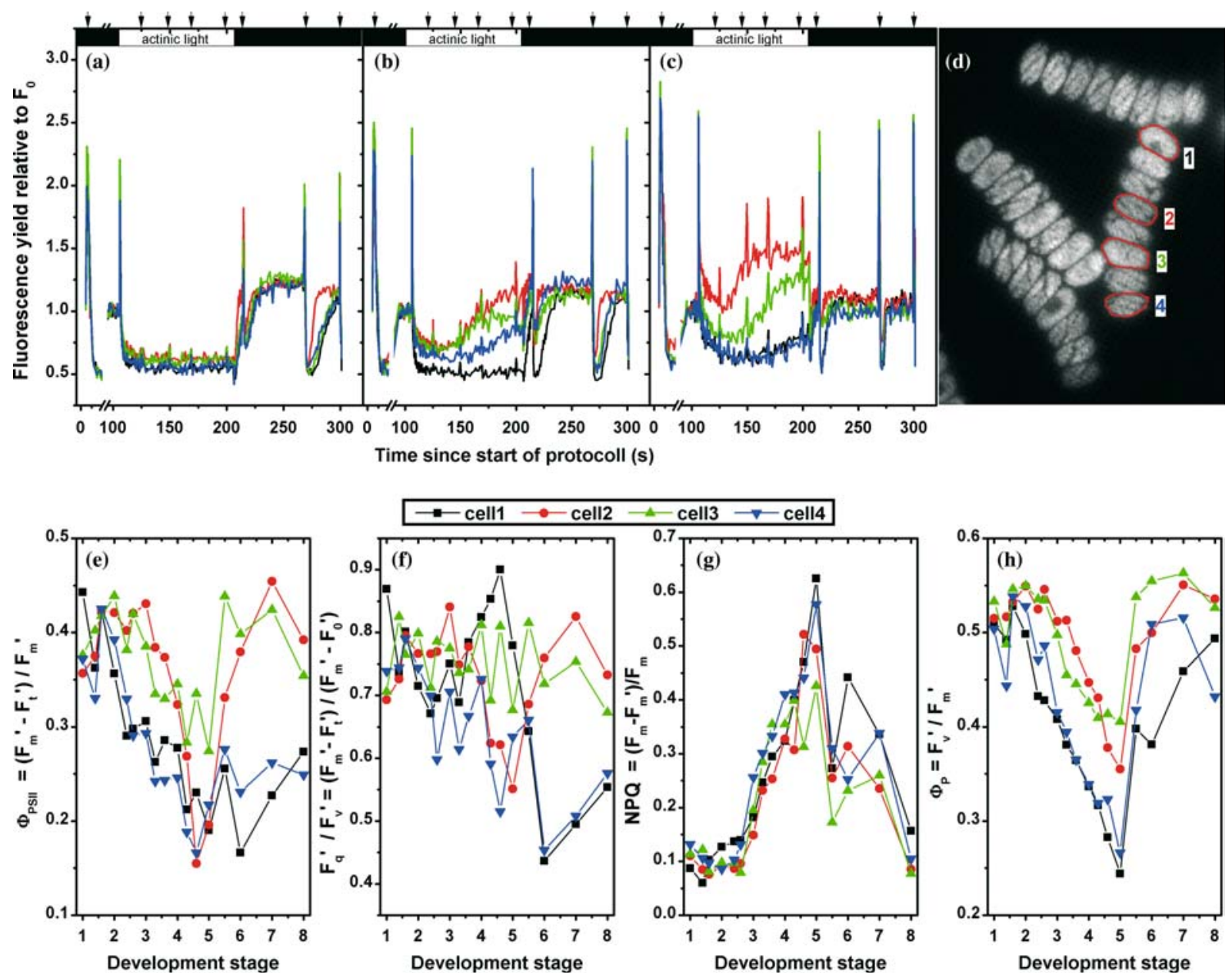

Figure 3. Heterogeneity in fluorescence response of individual cells in one Scenedesmus quadricauda coenobium. Four cells (labeled by numbers) selected in the image for analysis with the FluorCam software are shown in (d). (a-c) show the records of Kautsky fluorescence transient (elicited by actinic irradiance of $40 \mu \mathrm{mol} \mathrm{m}^{-2} \mathrm{~s}^{-1}$ ) of the four cells in three CC stages (5-7). The curves reveal the gradual changes in divergence among their shapes with progress of the CC. $(\mathrm{e}-\mathrm{h})$ show the variation of fluorescence parameters from these four cells in the course of the whole CC. Values of one typical example are shown, but the same course of development of this heterogeneity was observed in all cell cycles measured. The parameters plotted are indicated in the labelling of the $y$-axes, labelling of the curves is in the middle of the figure.

All facts described in this paper and questions that emerge from them call for more detailed investigations and analyses designed to approach their interpretation. We hope to have demonstrated convincingly that for this purpose the microscopic imaging of chlorophyll fluorescence is a promising method of choice.

\section{Acknowledgements}

Financial support was provided by the Ministry of Education of the Czech Republic, projects MSM6007665808, LN00A141 and 1P05ME824 and by the NATO collaborative project EST CLG 981009. The research at the Institute of Microbiology is supported by the Research concept AV0Z5020903. OP acknowledges financial support by the National Research Council fellowship No. 0269030.

\section{References}

Berková E, Doucha J, Kubín S, Zachleder V and Setlik I (1972) Variation in photosynthetic characteristics of Scenedesmus quadricauda during the cell cycle. In: G Forti (ed) Photosynthesis, Two Centuries after its Discovery by Joseph 
Pristley, 2nd International Congress on Photosynthesis Research, Stresa, June 24-29, 1971, pp 2619-2632. Dr. W. Junk Publishers, The Hague

Cournac L, Latouche G, Cerovic Z, Redding K, Ravenel J and Peltier G (2002) In vivo interactions between photosynthesis, mitorespiration and chlororespiration in Chlamydomonas reinhardtii. Plant Physiol 129: 1921-1928

Ferimazova N, Küpper H, Nedbal L and Trtílek M (2002) New insights into photosynthetic oscillations revealed by twodimensional microscopic measurements of chlorophyll fluorescence kinetics in intact leaves and isolated protoplasts. Photochem Photobiol 76: 501-508

Havelková-Doušová H, Prášil O and Behrenfeld MJ (2004) Photoacclimation of Dunaliella tertiolecta (Chlorophyceae) under fluctuating irradiance. Photosynthetica 42: 273-281

Küpper H, Šetlík I, Trtílek M and Nedbal L (2000) A microscope for two-dimensional measurements of in vivo chlorophyll fluorescence kinetics using pulsed measuring radiation, continuous actinic radiation, and saturating flashes. Photosynthetica 38: 553-570

Mende D, Heinze A and Wiessner W (1981) Chlorophyll a evolution and $\mathrm{O}_{2}$ evolution of synchronized Chlorella fusca. In: G Akoyunoglou (ed) Photosynthesis Proceedings of the 5th International Congress on Photosynthesis, Halkidiki, September 7-13, 1980, pp 473-480. Balaban International Sciences Services, Philadelphia

Oxborough K and Baker NL (1997) Resolving chlorophyll $a$ fluorescence images of photosynthetic efficiency into photochemical and non/photochemical components - calculation of $q P$ and $F_{V}^{\prime} / F_{M}^{\prime}$ without measuring $F_{0}^{\prime}$. Photosynth Res 54 : $135-142$
Oxborough K, Hanlon ARM, Underwood GJC and Baker NR (2000) In vivo estimation of the Photosystem II photochemical efficiency of individual microphytobenthic cells using high-resolution imaging of chlorophyll $a$ fluorescence. Limnol Oceanogr 45: 1420-1425

Peltier G and Cournac L (2002) Chlororespiration. Annu Rev Plant Biol 53: 523-550

Ried A, Šetlík I, Bossert U and Berková E (1973) The effect of low irradiances on oxygen exchange in green and blue-green algae. Photosynthetica 7: 161-176

Šetlík I, Berková E, Doucha J, Kubín Š, Vendlová J and Zachleder V (1972) The coupling of synthetic and reproduction processes in Scenedesmus quadricauda. Arch Hydrobiol 41 (Suppl.): 172-213

Šetlík I, Setlíková E, Masojídek J, Zachleder V, Kalina T and Mader P (1981) The effect of translation and transcription inhibitors on the development of the photosynthetic apparatus in cell cycles of Scenedesmus quadricauda. In: Akoyunoglou G (ed) Photosynthesis, Proceedings of the 5th International Congress on Photosynthesis, Halkidiki, September 7-13, 1980. pp 481-490. Balaban International Sciences Services, Philadelphia

Šetlík I and Zachleder V (1984) The multiple fission cell reproductive patterns in algae. In: Nurse $\mathrm{P}$ and Streiblová $\mathrm{E}$ (eds) The Microbial Cell Cycle, CRC Press, Boca Raton, Florida

Zachleder V, Bišová K, Vítová M, Kubín Š and Hendrychová J (2002) Variety of cell cycle patterns in the alga Scenedesmus quadricauda (Chlorophyta) as revealed by application of illumination regimes and inhibitors. Eur J Phycol 37: 361-371 